\title{
Reading in the operating room
}

\author{
Jan M. Davies, MD $\cdot$ Richard N. Merchant, MD
}

Received: 12 March 2015/ Accepted: 25 March 2015/Published online: 31 March 2015

(c) Canadian Anesthesiologists' Society 2015

\section{To the Editor,}

Usually found at the back of a journal, book reviews are often regarded as interesting but "light" supplements to the rest of a journal's editorial, scientific, and educational content. Nevertheless, book reviews are also worthy additions to a journal's content in that good reviews put forth "accepted criteria for evaluating science and practice" and "time-efficient sources" for scrutinizing trends. ${ }^{1}$ For example, even a relatively terse summary, such as "this book cannot be recommended", 2 could save the reader both hours of unsatisfying reading time as well as dollars.

Book reviews not only provide specifics about the book itself (e.g., its authors, organization, and content) but also impart information about the book's subject, sometimes alerting readers to the existence of "something new". Interestingly, some book reviews also reveal insights about the reviewer's "point of view". An example of this latter insight is conveyed in the April edition of the Journal. Specifically, the final line in one review states that the book "would be an excellent light read during a busy operating room day". 3

We recognize the challenges of maintaining minuteby-minute vigilance during prolonged cases when the patient's physiological condition seemingly appears unperturbed by the surgical procedure and the anesthetic agents. Such a lengthy case might be described as "not busy". In that context, we question what defines a "busy operating room day" and if one should self-distract during such a day by reading a textbook about complications. The irony was not lost on us.

Conflict of interest The authors attest that there are no affiliations providing a conflict of interest with this work and no sources of funding. Dr. Merchant is Chair of the Canadian Anesthesiologists' Society Standards Committee.

\section{References}

1. Jones RG, Fleenor J, Summers L. Book reviews and scientistpractitioner currency: a critical lever. The IndustrialOrganizational Psychologist 2004; 41: 22-5.

2. Karski JM. Hemostasis in cardiac surgery. Can J Anesth 1999; 46: 1099.

3. Dubois D. Complications and mishaps in anesthesia. cases analysis - preventive strategies. Can J Anesth 2015; 62: 437-8.

J. M. Davies, MD ( $\varangle)$

University of Calgary \& Foothills Medical Centre, Calgary,

$\mathrm{AB}$, Canada

e-mail: jdavies@ucalgary.ca

R. N. Merchant, MD

University of British Columbia \& Royal Columbian Hospital,

New Westminster, BC, Canada 